\title{
Laboratory-Scale Processing and Performance Assessment of Ti-Ta High-Temperature Shape Memory Spring Actuators
}

\author{
A. Paulsen ${ }^{1} \cdot$ H. Dumlu ${ }^{1}$ D. Piorunek ${ }^{1} \cdot$ D. Langenkämper ${ }^{1} \cdot$ J. Frenzel $^{1} \cdot$ \\ G. Eggeler ${ }^{1}$
}

Received: 30 April 2021/Revised: 25 May 2021/Accepted: 26 May 2021/Published online: 21 June 2021

(C) The Author(s) 2021

\begin{abstract}
Ti}_{75} \mathrm{Ta}_{25}$ high-temperature shape memory alloys exhibit a number of features which make it difficult to use them as spring actuators. These include the high melting point of Ta (close to $3000{ }^{\circ} \mathrm{C}$ ), the affinity of Ti to oxygen which leads to the formation of brittle $\alpha$-case layers and the tendency to precipitate the $\omega$-phase, which suppresses the martensitic transformation. The present work represents a case study which shows how one can overcome these issues and manufacture high quality $\mathrm{Ti}_{75} \mathrm{Ta}_{25}$ tensile spring actuators. The work focusses on processing (arc melting, arc welding, wire drawing, surface treatments and actuator spring geometry setting) and on cyclic actuator testing. It is shown how one can minimize the detrimental effect of $\omega$ phase formation and ensure stable high-temperature actuation by fast heating and cooling and by intermediate rejuvenation anneals. The results are discussed on the basis of fundamental $\mathrm{Ti}-\mathrm{Ta}$ metallurgy and in the light of $\mathrm{Ni}-\mathrm{Ti}$ spring actuator performance.
\end{abstract}

Keywords High-temperature shape memory alloys (HTSMAs) - Ti-Ta $\cdot \omega$-Phase $\cdot$ Martensitic transformation . Lab scale processing . Actuator performance

This article is part of a special topical focus in Shape Memory and Superelasticity on the Mechanics and Physics of Active Materials and Systems. This issue was organized by Dr. Theocharis Baxevanis, University of Houston; Dr. Dimitris Lagoudas, Texas A\&M University; and Dr. Ibrahim Karaman, Texas A\&M University.

J. Frenzel

jan.a.frenzel@rub.de

1 Institute for Materials, Ruhr University Bochum, Universitätsstr. 150, 44801 Bochum, Germany

\section{Introduction}

Towards the turn of the millennium materials science and technology of shape memory alloys (SMAs) had reached a level, which allowed to realize many interesting shape memory applications in different fields of engineering and in medical technology [1-5]. At the time $\mathrm{Ni}-\mathrm{Ti}$ based SMAs were in the focus of interest, because their structural and functional properties made them the commercially most successful SMAs. In the last two decades traditional and new processing techniques were analyzed from a fundamental and technological point of view [6-10]. Moreover, new alloy systems received considerable attention, including Ni-free shape memory alloys [11], highentropy SMAs [12-15] and high-temperature SMAs (HTSMAs) [16-19]. Ma et al. [18] have pointed out that SMAs with high transformation temperatures can enable simplifications and improvements in operating efficiency of many functional components designed to operate at temperatures above $100{ }^{\circ} \mathrm{C}$ in the automotive, aerospace, manufacturing and energy exploration industries. Seminal work from the Miyazaki group [20-22] focused on the TiTa system as a potential HTSMA. Ti-Ta alloys, which belong to the larger family of $\beta$-Ti alloys [23], are attractive because they do not contain expensive noble metals and exhibit excellent cold-workability [22, 24]. In recent years, a group of German materials researchers funded by the German Research Foundation (DFG) [25] has studied the Ti-Ta system. The microstructural evolution during ingot metallurgy processing was investigated $[24,26]$. The influence of oxidation on the martensitic transformation in the surface region was investigated [27]. Atomistic calculations on the stability of phases, especially the $\omega$-phase, were performed [28-30]. Special emphasis was placed on the role of the $\omega$-phase during functional fatigue of $\mathrm{Ti}-\mathrm{Ta}$ 
alloys [31-34] and it has been shown that by controlling the temperature during heating and cooling one can counteract fast functional degradation by $\omega$-phase precipitation. Functional fatigue was so far studied using uniaxial specimens. The objective of the present work is to document how one can prepare $\mathrm{Ti}-\mathrm{Ta}$ spring actuators and assess their performance in comparison to conventional $\mathrm{Ni}-\mathrm{Ti}$ spring actuators $[35,36]$.

\section{Experiments}

\section{Ingot Metallurgy and Microstructural Analysis}

In the present study, $\mathrm{Ti}_{75} \mathrm{Ta}_{25}$ HTSMA spring actuators were prepared following an ingot metallurgical processing route which involves arc melting (AM), arc welding, heat treatments, thermomechanical processing and shape setting. First, $\mathrm{Ti}_{75} \mathrm{Ta}_{25}$ (at.\%) ingots with masses close to $45 \mathrm{~g}$ were prepared by AM using high-purity Ti (99.995 wt\%) and Ta (99.95 wt\%) raw materials obtained from Hauner Metallische Werkstoffe (Röttenbach, Germany). An arc melter of type Bühler AM was used to prepare the alloys. Figure 1 provides an overview summary of the individual steps involved in arc melting. The feedstock raw materials are shown in Fig. 1a. Figure $1 \mathrm{~b}$ represents a view into the chamber of the arc melter, where one can see a hot button shaped ingot. All details of the melting process have been published elsewhere [24, 37]. Ti-Ta ingots of $45 \mathrm{~g}$ were remelted 15 times to ensure chemical homogeneity of the ingot. Prior to each cooling step the melts were kept $20 \mathrm{~s}$ in the liquid state to promote sufficient mixing. A drop cast ingot which was produced following this procedure is shown in Fig. 1c. The high melting temperature of $\mathrm{Ti}_{75}$ $\mathrm{Ta}_{25}$ [38] and the limited power of our laboratory arc melter did not allow to make larger ingots of sufficient homogeneity. However, larger alloy volumes were required for subsequent thermo mechanical processing (rolling and wire drawing). Therefore, two ingots of cuboidal shape were produced and combined by welding in the arc melter. Figure 1d shows the two ingots next to each other. Figure 1e shows the two ingots during cooling after the first welding step on one side. The resulting larger material volume after the complete joining procedure is shown in Fig. 1f. Prior to thermo mechanical processing, this elongated block was solution heat treated at $1100{ }^{\circ} \mathrm{C}$ for $25 \mathrm{~h}$ under vacuum to minimize microscale heterogeneities associated with dendritic solidification as described by Zhang et al. [24].

Optical and scanning electron microscopy (OM and SEM) were used to characterize the microstructures of the Ti-Ta HTSMAs. Samples were prepared following conventional metallographic procedures which have been documented previously [e.g. 34]. An optical microscope of Type Zeiss Axio Imager A1m was used to evaluate grain structures in as-cast and thermo mechanically processed material states. Good contrast was obtained using polarized light after etching with a solution consisting of $50 \mathrm{ml}$ Beraha-II-solution [39] and 0.5 g potassium disulfite. SEM images were taken with the help of a FEI ESEM Quanta FEG 650. Details regarding SEM imaging were published previously [e.g. 34].

\section{Thermo Mechanical Treatments and Wire Drawing}

The homogenized ingots were subjected to a processing route which started with hot rolling, swaging, wire drawing and intermediate heat treatments. This processing route was developed and documented previously [35, 36, 40]. Fully recrystallized wires with a diameter of $0.8 \mathrm{~mm}$ were obtained, from which helical coil spring actuators were manufactured. Figure 2 provides an overview summary of seven processing steps. First, the homogenized $\mathrm{Ti}-\mathrm{Ta}$ ingots with dimensions close to $17 \mathrm{~mm} \times 17 \mathrm{~mm} \times 60$ $\mathrm{mm}$ were hot rolled after pre-heating to $800{ }^{\circ} \mathrm{C}$, using a Bühler DW rolling mill. The cuboidal ingots were shaped into rods with hexagonal cross sections (steps 1 and 2 in Fig. 2). The hexagonal rods were pre-heated at $800{ }^{\circ} \mathrm{C}$ and hot rolled further, using a Krollmann DWU 30 machine to make thin cylindrical rods of $11.3 \mathrm{~mm}$ diameter (3 in Fig. 2). After a $10 \mathrm{~min}$ recrystallization treatment at $850{ }^{\circ} \mathrm{C}$, swaging was performed using a HMP R6-4-12021S machine. Eight swaging steps were applied, each associated with $63 \%$ reduction of diameter, to reach a final diameter of $5.4 \mathrm{~mm}$ (4 in Fig. 2).

From this final swaging state wires were made using a HMP ZPR 20006 wire drawer, equipped with cemented carbide drawing dies with decreasing diameters (4-6 in Fig. 2). A lubricant of type RVP $55 \mathrm{~K}$ from Holifa (Hagen, Germany) was used to minimize friction. Diamond coated dies were used in the final drawing steps. Intermediate $800{ }^{\circ} \mathrm{C} / 10 \mathrm{~min}$ annealing steps were carried out at wire diameters of $4.26,3.45,2.80,2.27,1.84,1.54$ and $1.21 \mathrm{~mm}$. The final wire with a diameter of $0.8 \mathrm{~mm}$ (6 in Fig. 2) was fully recrystallized at $900{ }^{\circ} \mathrm{C}$ for $10 \mathrm{~min}$. The microstructure of the alloy and the surface quality of the thermo mechanically treated material evolve as documented in Figs. 3 and 4. The microstructure of the as-cast Ti-Ta alloy as observed in the optical microscope is shown in Fig. 3a, where one can distinguish a typical martensitic microstructure within a network of prior austenite grain boundaries (prior austenite grain size after casting and homogenization annealing: $d \approx 300 \mu \mathrm{m}$ ). Thermo mechanical processing and wire drawing with intermediate anneals refines this microstructure as shown in Fig. 3b, where martensite has formed within prior austenite grains 

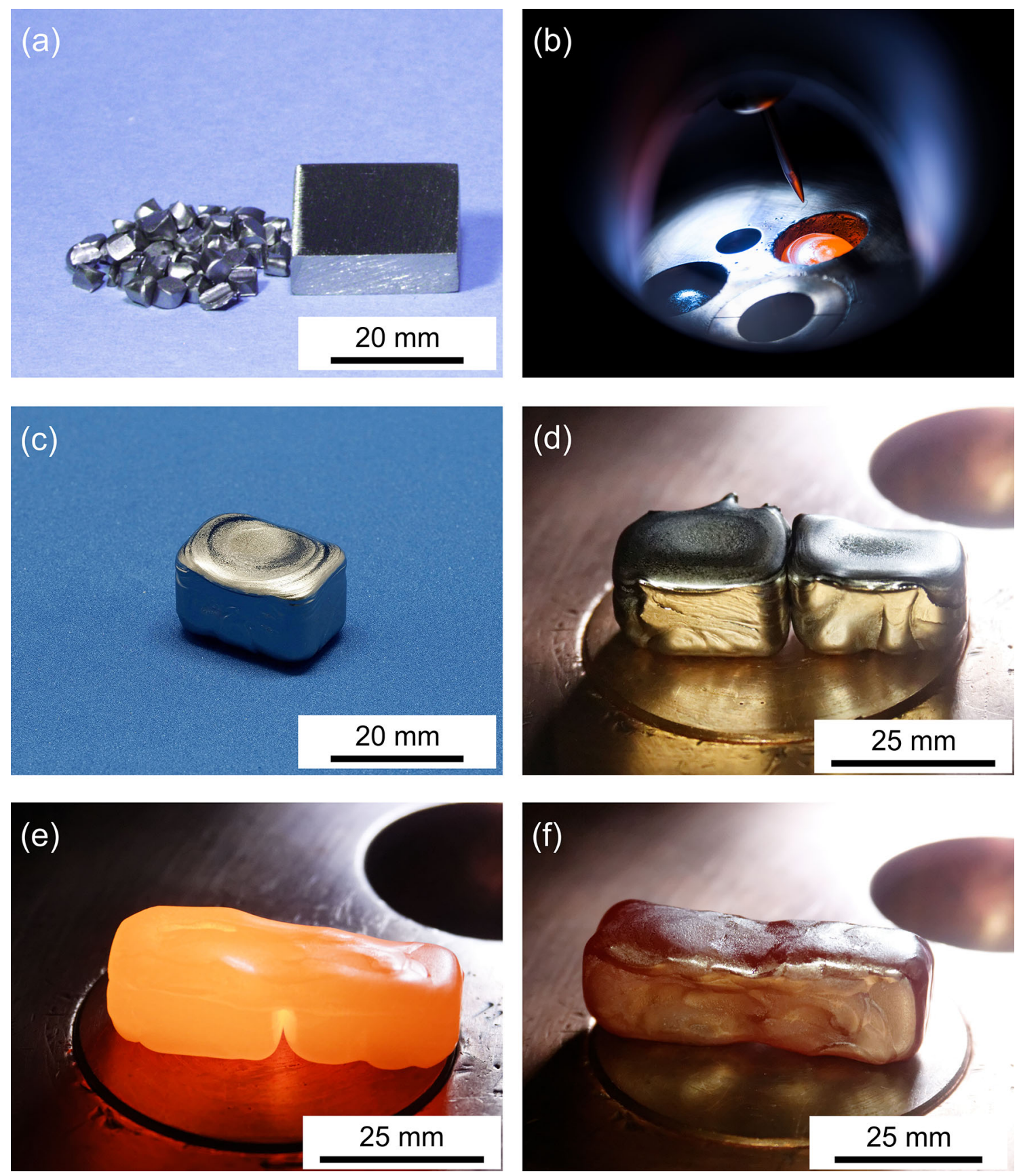

Fig. 1 Illustration of melting/welding procedure to produce starting material for subsequent homogenization heat treatment and thermo mechanical processing. a Feedstock (Ta chunks and Ti plate). b Arc

which are almost ten times smaller (prior austenite grain size after wire drawing with intermediate anneals: $d \approx$ $40 \mu \mathrm{m})$.

Care has to be taken in view of the fact that Ti-Ta alloys rapidly oxidize, due to the high affinity of $\mathrm{Ti}$ to oxygen [11, 23, 27]. Even though all heat treatment steps were performed under protective Argon atmosphere, an oxide layer known as $\alpha$-case layer forms, which is hard and brittle, where microcracks can form [23]. Figure 4 presents

melting. c Cuboidal $\mathrm{Ti}_{75} \mathrm{Ta}_{25}$ ingot after drop casting. d-f Joining two ingots by arc welding for sufficient material volume

four SEM micrographs which show surface damage related to $\alpha$-case formation and crack formation during processing. Figure $4 \mathrm{a}$ shows the presence of an $\alpha$-case layer with a thickness close to $40 \mu \mathrm{m}$ after swaging (material state 4 in Fig. 2). The thickness of this surface zone increased during wire drawing and associated intermediate heat treatments, Fig. $4 \mathrm{~b}$ and c. During wire drawing the surface damage increases, Fig. $4 \mathrm{~b}$ and c. In order to improve the surface quality of the final material state, surface layers of $150 \mu \mathrm{m}$ 
thickness were removed by grinding, after the wire diameter was reduced to $1.2 \mathrm{~mm}$. Figure $4 \mathrm{~d}$ documents that this grinding treatment allowed to improve the quality of the surface region, however, the presence of small cracks could not be fully avoided. Further work is required to improve the surface quality of the material, for example by electrochemical polishing.

\section{Spring Actuator Processing}

20 turn helical coil spring actuators (material state 7 in Fig. 2) with an active length of $16 \mathrm{~mm}$ and an inner diameter of $4.9 \mathrm{~mm}$ were prepared from recrystallized wires by applying a shape setting procedure. The spring geometry was developed for testing $\mathrm{Ni}-\mathrm{Ti}$ and $\mathrm{Ni}-\mathrm{Ti}-\mathrm{Cu}$ actuators with different compositions and after different thermo mechanical treatments $[35,36,40]$. Figure 5

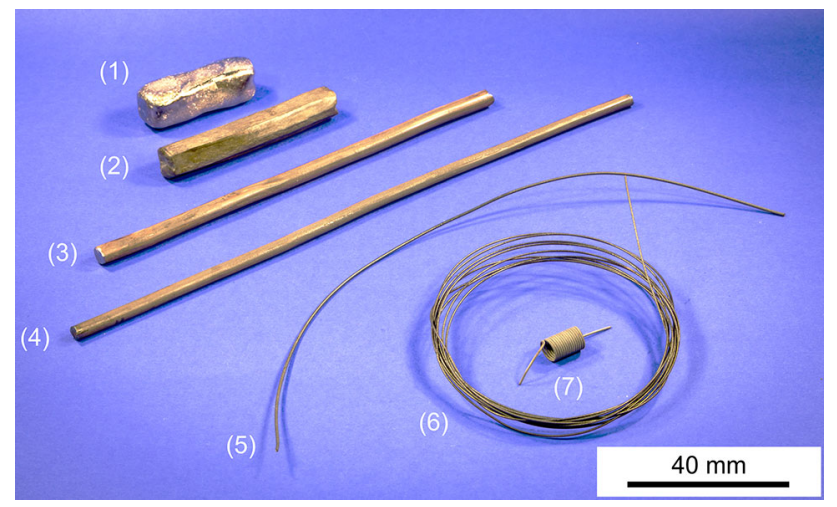

Fig. 2 From arc melted ingots to spring actuators. (1) Starting material after arc melting and arc welding. (2) Hot rolled bar with hexagonal cross section (max. cross section: $15 \mathrm{~mm}$ ). (3) Small cylindrical swaged bar (diameter: $9 \mathrm{~mm}$ ). (4) $5.4 \mathrm{~mm}$ cylindrical bar after swaging. $(5,6)$ Material after wire drawing. (7) Actuator spring

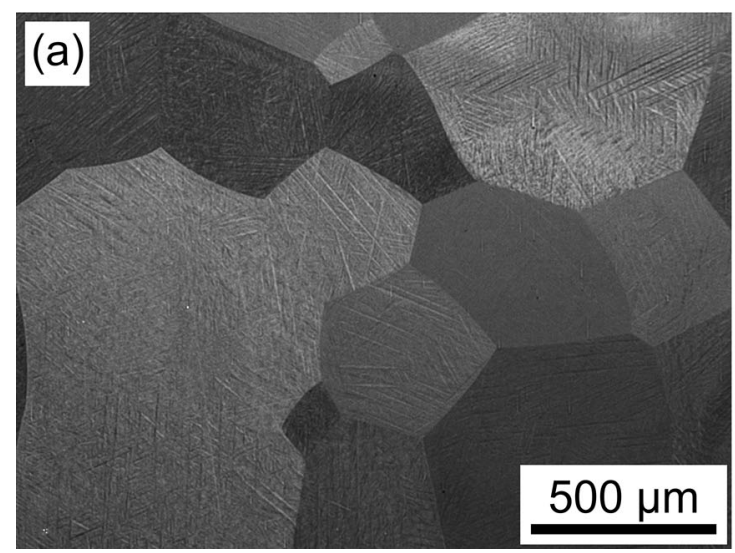

Fig. 3 Optical micrographs of prior austenite grains with lath/plate like martensitic microstructures. a Microstructure of ingot after arc melting and solution annealing (material state shown in Fig. 1c, prior illustrates the shape setting procedure. The shape setting tool in Fig. 5a consists of two steel disks which can be fixed by screws onto a cylindrical steel shaft. Figure $5 \mathrm{~b}$ shows the beginning of spring winding, the wire, which is fixed in a hole in the right cylindrical disk is fed through a second hole in the left cylindrical disk and held in place during spooling. The material states prior to and after the shape setting heat treatment are presented in Fig. $5 \mathrm{c}$ and d, respectively. The shape setting process was carried out at $900{ }^{\circ} \mathrm{C}$ for $5 \mathrm{~min}$ followed by water quenching. Note that this temperature is significantly higher than the temperatures which are typically considered for the shape setting for Ni-Ti-based SMA spring actuators. It was chosen to avoid the formation of $\alpha$-Ti and $\omega$-phase, which downgrade the functional performance of Ti-Ta HTSMAs [20-22, 31-34].

\section{Phase Transition Temperatures and Spring Actuator Testing}

The phase transition temperatures were evaluated using a differential scanning calorimeter (DSC). Specimens with masses close to $50 \mathrm{mg}$ were investigated in an instrument of type TA $2920 \mathrm{CE}$. The heating and cooling rates were $20 \mathrm{~K} / \mathrm{min}$. All experiments were carried out under an $\mathrm{Ar} /$ $\mathrm{He}$ atmosphere. The start and finish temperatures of the martensitic transformation $\left(\mathrm{M}_{\mathrm{S}}\right.$ and $\left.\mathrm{M}_{\mathrm{F}}\right)$ and of the reverse transformation $\left(A_{S}\right.$ and $\left.A_{F}\right)$ were determined using the tangent method. All details on DSC sample preparation and test procedures are given in [34]. The cyclic functional performance of the Ti-Ta spring actuators was characterized using a test rig design which was described by Grossmann et al. [35, 36]. In this test rig a typical cycle consists of a pseudoplastic deformation caused by the end load, which sinks to a lowest position $x_{\mathrm{M}}$. On heating, the

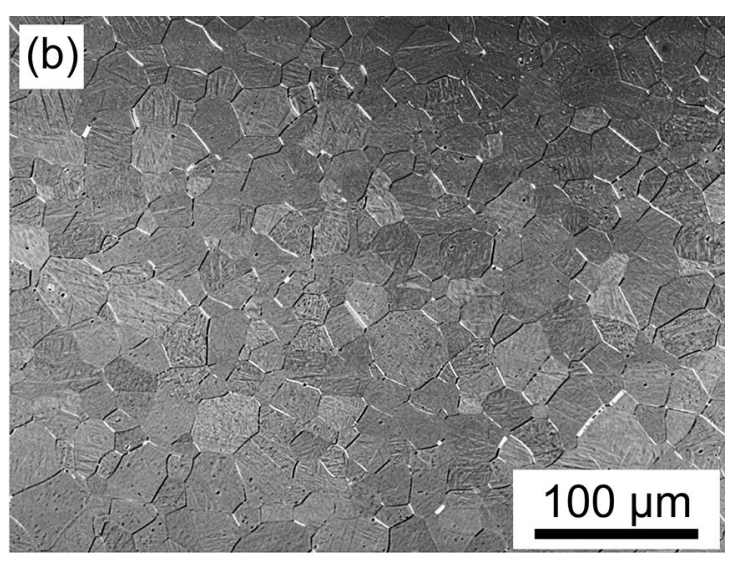

austenite grain size: $d \approx 300 \mu \mathrm{m}$ ). b Microstructure of wire (material state 6 in Fig. 2, prior austenite grain size: $d \approx 40 \mu \mathrm{m}$ ) 
(a)

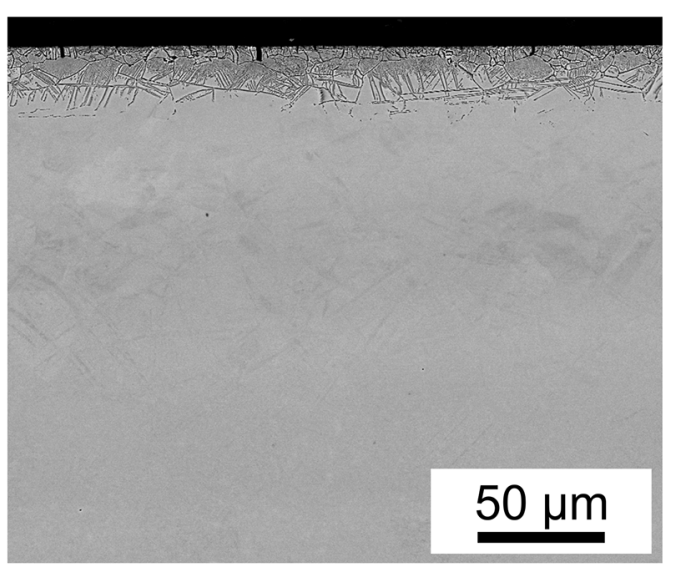

(c)

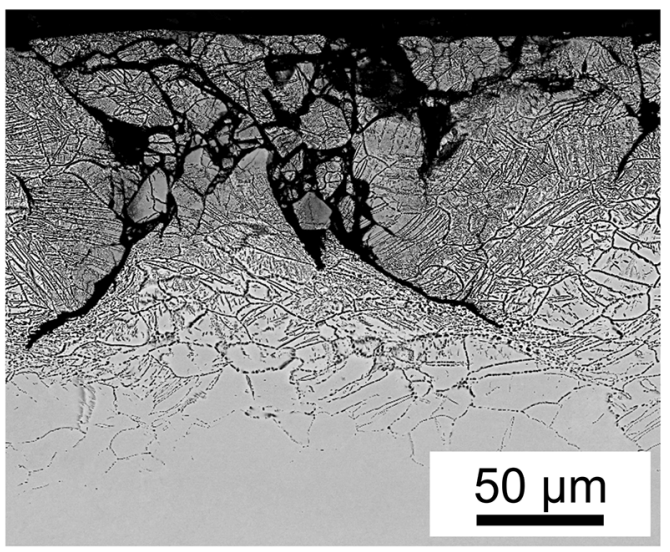

Fig. 4 SEM micrographs documenting the presence of surface damage associated with the formation of a brittle $\alpha$-case layer. a Surface region after swaging (material state 4 in Fig. 2). b Wire

spring contracts and lifts the end load to the position $x_{\mathrm{A}}$. The position $x$ of the end load during its vertical up and down movement is measured with a laser sensor. This rig was adapted for HTSMA testing [41] using stronger grips to ensure sufficient electrical contact and by using a stronger electrical power source. The tensile-loaded Ti-Ta spring actuators worked against an end load of $2 \mathrm{~N}$ and were subjected to subsequent heating/cooling cycles at constant heating/cooling rates of $10 \mathrm{~K} / \mathrm{s}$. The load of $2 \mathrm{~N}$ results in a maximum shear stress of $61 \mathrm{MP}$ in the surfacenear volume of the fully contracted spring actuator [36]. This shear stress corresponds to a von Mises reference stress of $105 \mathrm{MPa}$, which is significantly larger than the minimum bias stress level reported in Ref. [42] for a $\mathrm{Ti}_{70} \mathrm{Ta}_{30}$ HTSMA. The two photographs in Fig. 6 show the actuator spring in the test rig during operation, where the vertical up and down movement of the end load in the test rig (not shown here, see schematic Fig. 1 in [35]) results in a horizontal contraction/expansion of the actuator spring. The key elements of the test rig are highlighted in Fig. 6a. (b)

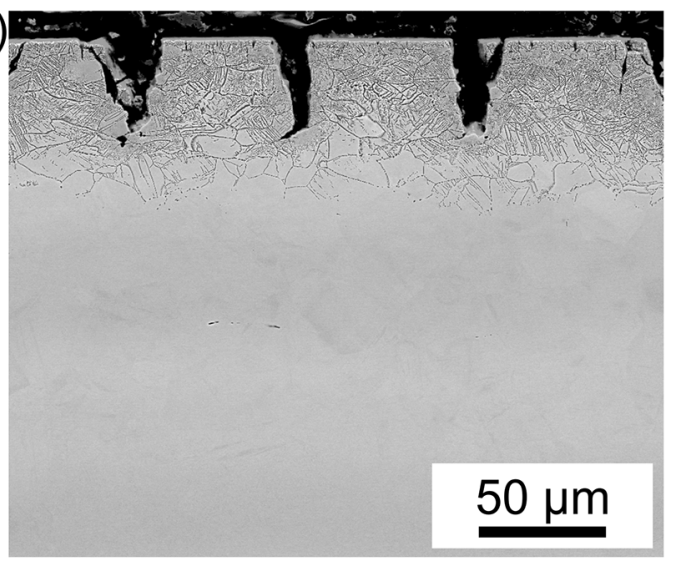

(d)

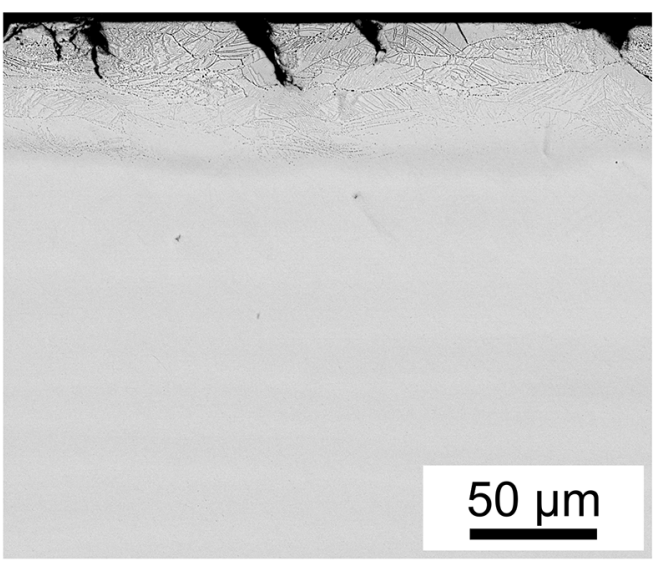

surface damage for a wire thickness $d=3.4 \mathrm{~mm}$. c Wire surface damage for a wire thickness $d=1.2 \mathrm{~mm}$. d Reduced wire surface damage for final wire thickness of $d=0.8 \mathrm{~mm}$, after grinding

The setup consists of a load cell (1), grips allowing electric current heating and clamping the specimen (2), a $0.25 \mathrm{~mm}$ diameter type $\mathrm{K}$ thermocouple in direct contact with the spring actuator (4), a low friction linear slide system (5) and a fan array for cooling (6). Constant heating/cooling rates were established using a laboratory power source of type EA-PS 9032-40 from Elektro-Automatik (Viersen, Germany). The experiment was controlled by a self-designed software installed on a conventional personal computer.

Constant cooling rates of $10 \mathrm{~K} / \mathrm{s}$ were achieved by letting the fan array blow air onto the spring which is still subjected to a low constant heating current. An optical displacement sensor (not shown here) was used to monitor the evolution of the spring geometry, i.e. the change of the position of the slide ( 5 in Fig. 6 a). The thermocouple ( 3 in Fig. 6a) served to control heating/cooling rates. An infrared camera of Type VarioTherm from InfraTec $\mathrm{GmbH}$ (Dresden, Germany) allowed to monitor the temperature distributions in the springs. In Fig. 6a, the color-coded 

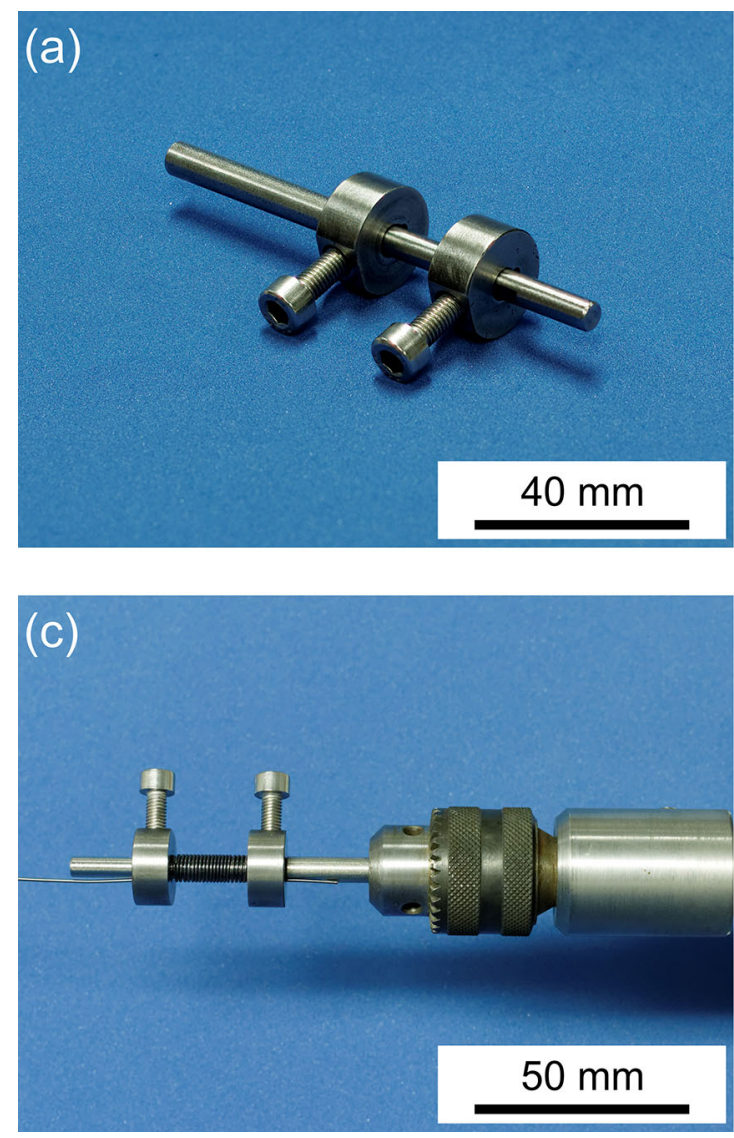

Fig. 5 Illustration of actuator spring processing. a Shape setting tool consisting of a cylindrical shaft (diameter $=$ inner diameter of final spring) and two discs with fixing screws. b Start of recoiling. Tool shaft fixed to motor, wire fixed to right disk (can be seen to stick out),

temperature distribution chart shows that the spring specimen is at a temperature of $250{ }^{\circ} \mathrm{C}$ (blue color). Figure 6a and $\mathrm{b}$ actually represent the beginning and the end of $\mathrm{a}$ heating cycle. In Fig. $6 \mathrm{~b}$, towards the end of the heating cycle, the spring temperature has reached $450{ }^{\circ} \mathrm{C}$ (yellow/ orange color).

\section{Results}

\section{DSC Charts}

We first compare the thermal transformation behavior of the heat treated ingot (1 in Fig. 2) and the as-processed actuator spring (7 in Fig. 2). A DSC chart of the as-cast and solution annealed ingot is shown in Fig. 7a. The DSC experiment started with heating from room temperature to $350{ }^{\circ} \mathrm{C}$, red curve in Fig. 7a. The endothermal strong and sharp peak 1 indicates the transformation from martensite to austenite. At $350{ }^{\circ} \mathrm{C}$ cooling started without delay and the blue curve was recorded. On cooling one first observes
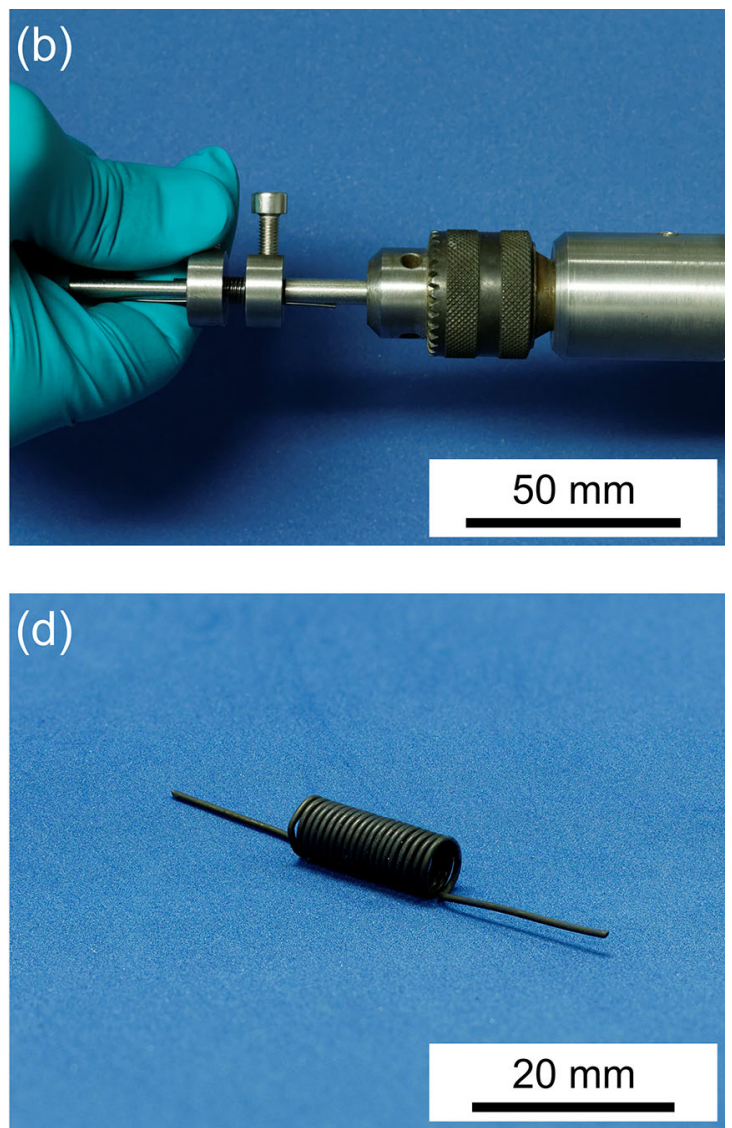

wire is fed through the hole in left disk. c Wire wound up and constrained into spring shape prior to shape setting heat treatment. d Actuator spring as used for functional fatigue testing

a small but well-defined peak 2 which results from a superposition of an overshoot associated with the abrupt change from heating to cooling and the formation of the $\omega$ phase [41, 43-45]. The features of the other DSC charts presented in Fig. 7a and b, which look very different from what is typically observed for Ni-Ti SMAs, can only be appreciated when one considers the effect of the formation, dissolution and re-precipitation of $\omega$-phase [41, 43-45]. The smaller irregular peak 3 which follows represents the transformation from austenite to martensite, hampered by the formation of the $\omega$-phase which forms quickly $[30,32,34]$. From the experiment shown in Fig. 7a one can derive austenite and martensite peak temperatures of $299{ }^{\circ} \mathrm{C}$ (red maximum recorded on heating) and $280{ }^{\circ} \mathrm{C}$ (second irregular blue maximum recorded on cooling).

Figure 7b shows two DSC charts recorded for the thermo mechanically processed spring in two subsequent heating/cooling cycles. The first cycle (solid red and blue DSC curves) was recorded imposing the same heating/cooling conditions as in Fig. 7a. A broad and weak red endothermic peak 1 on heating represents the 
transformation from martensite to austenite. It is weaker than in the case of the heat-treated ingot in Fig. 7a, because the microstructure of the thermo mechanically treated spring most probably promotes the $\omega$-formation more strongly. Since the transformation is not complete, one can

(1)

(2)

(3) (4)

(5) (6)

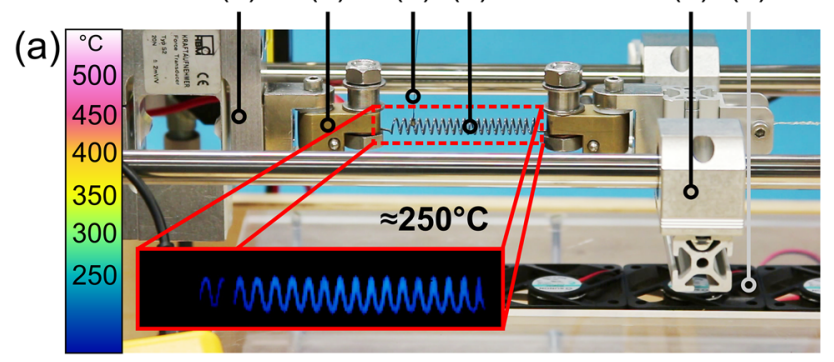

(b)

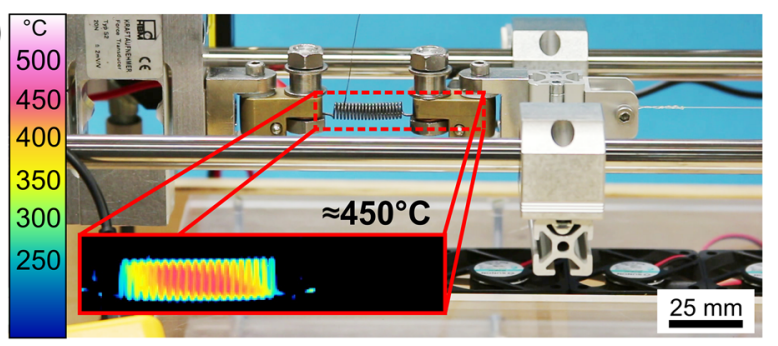

Fig. 6 Test rig for assessing Ti-Ta HTSMA spring actuator performance. The two photographs were taken during a heating cycle. The insets show color coded temperature distributions recorded with an IR-thermo camera. Key elements of the test rig are highlighted in a 1-load cell; 2-grips (for mechanical clamping)/electrical contacts (for direct current heating); 3 - control thermo couple; 4-Ti-Ta spring; 5-low friction linear slide system; 6-fan array (for air cooling). a Begin of heating cycle, $T \approx 250{ }^{\circ} \mathrm{C}$. b Reaching end of heating cycle, $T \approx 450{ }^{\circ} \mathrm{C}$

(a)

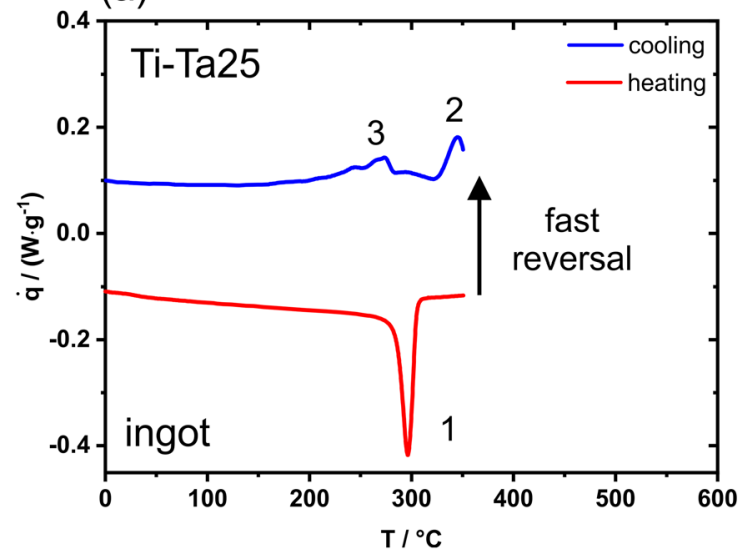

Fig. 7 DSC charts recorded for $\mathrm{Ti}_{75} \mathrm{Ta}_{25}$. a Homogenized ingot. The DSC experiment starts with heating (red solid line). The black arrow indicates a fast transition from heating to cooling (blue solid line). Peak 1: Martensite/austenite transition. Peak 2: Overshoot due to fast temperature change and formation of $\omega$-phase. Peak 3: Reverse transformation from austenite to martensite. b Material taken from spring actuator. Two heating cooling cycles with different maximum hardly recognize the reverse transformation in the blue solid DSC chart associated with the cooling part of the first cycle (region with smeared out heat effects of DSC chart marked with 2). In the second cycle, the transformation peak, which one would expect for the transformation from martensite to austenite, can hardly be identified, partly because less martensite had formed in the cooling period of the first cycle and also because $\omega$-phase is present. The broad weak exothermic maximum at $450{ }^{\circ} \mathrm{C}$ (marked with a 3 ) indicates that nucleation and growth of $\omega$-phase proceeds. Above $500{ }^{\circ} \mathrm{C}$, the $\omega$-phase dissolves which gives rise to a pronounced endothermic peak 4 with a maximum at $520{ }^{\circ} \mathrm{C}$. On cooling, the $350{ }^{\circ} \mathrm{C}$ exothermic peak 5 (observed at a significantly higher temperature as the austenite/martensite transformation in Fig. 7a) is associated with the re-precipitation of $\omega$-phase and no martensite peak is observed. The results presented in Fig. 7 clearly suggest that faster heating/cooling are required in order to exploit the one way effect for actuation.

\section{Actuation and the Effect of Intermediate Anneals}

Figure 8 shows results from spring actuator tests which started at room temperature and were heated up to maximum temperatures $T_{\max }$ of 450 and $550{ }^{\circ} \mathrm{C}$ at heating rates of $10 \mathrm{~K} / \mathrm{s}$, significantly faster than those applied during DSC testing in Fig. 7.

Cooling started as soon as the maximum temperature was reached, the time spent at $T_{\max }$ was only a few seconds. The results for $T_{\max }=450{ }^{\circ} \mathrm{C}$ are presented in Fig. 8a, where the spring position $x$ is plotted as a function of the temperature. In the first cycle (red curves), the spring

(b)

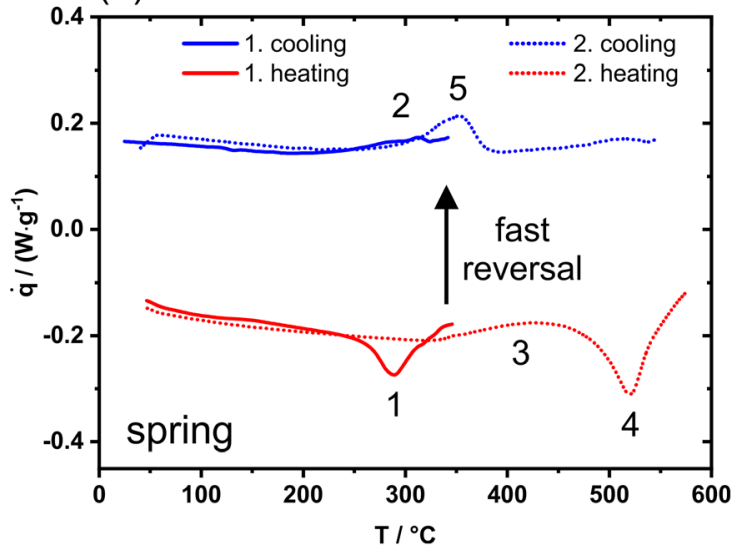

temperatures. Black arrow indicates a fast transition from heating (red solid line) to cooling (blue solid line). Second cycle: specimen was heated to higher temperature. Red and blue dotted lines: heating and cooling charts of second cycle. Peak 1: Martensite/austenite transformation. Exothermic region 2: Small amount of martensite forms. Endothermic peak 3: Formation of $\omega$-phase. Peak 4: Dissolution of $\omega$ phase. Peak 5: $\omega$-phase formation 

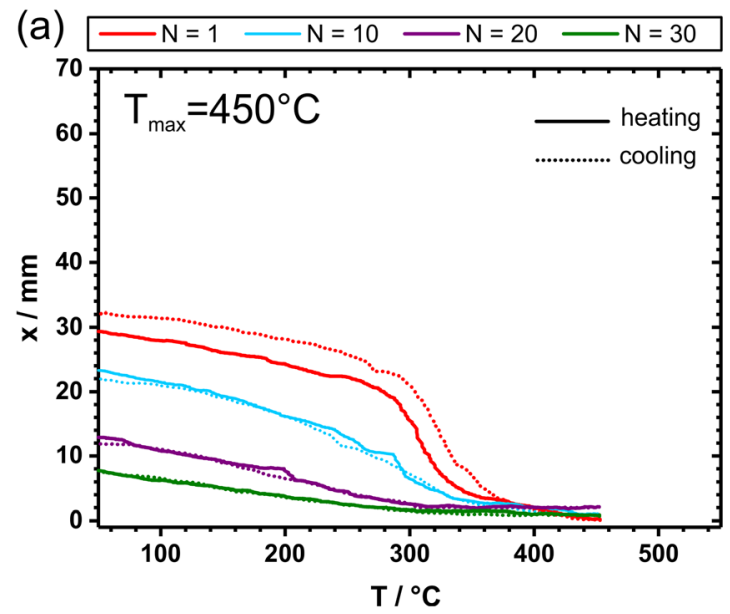
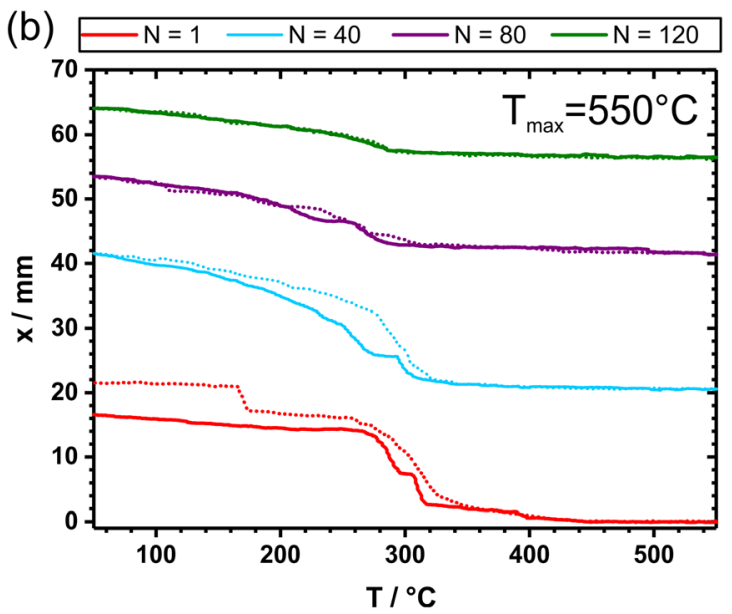

Fig. $8 \mathrm{Ti}_{75} \mathrm{Ta}_{25}$ spring actuator response monitored at heating/cooling rates of $10 \mathrm{~K} / \mathrm{s}$. The results are presented as displacement $x$ vs. temperature $T$ curves. a $T_{\max }=450{ }^{\circ} \mathrm{C} ; \mathbf{b} T_{\max }=550{ }^{\circ} \mathrm{C}$

actuator contracts from its expanded martensite state $\left(x_{\mathrm{M}}\right.$ $\approx 30 \mathrm{~mm})$ to its austenite state $\left(x_{\mathrm{A}} \approx 0 \mathrm{~mm}\right)$, resulting in a stroke $\Delta x\left(\Delta x=x_{\mathrm{M}}-x_{\mathrm{A}}\right)$ of $30 \mathrm{~mm}$ (red solid line). On cooling, the expanded shape is almost fully re-established (red dotted line). In all cooling curves (dotted lines) the reverse transformation of austenite to martensite is observed at temperatures $\mathrm{M}_{\mathrm{S}}$ which are slightly higher than $A_{S}$. With increasing cycle numbers, the elongation of the spring associated with the formation of martensite on cooling decreases significantly. After 30 cycles, the resulting stroke is reduced to $8 \mathrm{~mm}$ (green curves in Fig. 8a). The behavior observed in Fig. $8 \mathrm{~b}$ for a higher $T_{\max }$ of $550{ }^{\circ} \mathrm{C}$ differs significantly. First, it takes as many as 120 cycle to reduce the stroke from 20 to $8 \mathrm{~mm}$. Second, one observes a time dependent plastic deformation which results in an irreversible elongation of the spring, associated with shifts of both positions $x_{\mathrm{M}}$ and $x_{\mathrm{A}}$ towards higher values. The green curves show the actuator response after 120 cycles, where the spring (in both states) has increased its length by $45 \mathrm{~mm}$ (in the martensitic state) respectively $60 \mathrm{~mm}$ (in the austenitic state). As will be discussed in detail later, the precipitation of $\omega$-phase causes the fast degradation of functional performance observed for a $T_{\max }$ of $450{ }^{\circ} \mathrm{C}$ in Fig. 8a. At the higher $T_{\max }$ considered for the experiments compiled in Fig. $8 \mathrm{~b}$, the $\omega$-phase dissolves and functional fatigue life increases.

Figure 9 illustrates, that intermediate anneals at $550{ }^{\circ} \mathrm{C}$ can help to significantly improve functional fatigue performance. The plots in Fig. 9 are of the same $x$ vs. $T$ type as those shown in Fig. 8. The four $x(T)$-charts show results which were obtained for the initial state, Fig. 9a, and after intermediate anneals, Fig. 9b-d. The results shown in Fig. 9a correspond to the findings presented in Fig. 8a, we observe the decrease in stroke with increasing thermo mechanical cycle numbers. After 15 cycles, the actuator spring specimen was subjected to a short $10 \mathrm{~s}$ in-situ intermediate anneal at $550{ }^{\circ} \mathrm{C}$. Note that this intermediate anneal was performed by direct current heating in the fatigue test rig, however, under load-free conditions. As can be seen in Fig. 9b, this intermediate anneal almost fully re-establishes the functional performance of the initial state, but suffers the same type of degradation with increasing cycle numbers. During another 15 thermo mechanical cycles (numbered from 16 to 30 in Fig. 9b), the same type of degradation described for the initial state is observed. Then, a second intermediate heat treatment can again successfully re-establish initial state actuator strokes. Figure 9c and d, document that this beneficial effect can be exploited when intermediate anneals are repeated in 15 cycle intervals. Figure $9 \mathrm{c}$ and $\mathrm{d}$ show cycling sequences for cycles 61-75 (after the fourth intermediate anneal) and 121-135 (after the eighth intermediate anneal). Moreover, as can be seen in Fig. 9c and d, the combination of spring actuator cycling with intermediate anneals results in a more stable actuator performance and only slightly reduces the exploitable stroke. Figure 10 provides condensed information retrieved from the experiment shown in Fig. 9. It shows how the spring actuator stroke $\Delta x$ evolves during cyclic actuation (cycle number: $N$ ), when intermediate anneals are applied (number of intermediate anneal: $n$ ). At the beginning, strokes decrease with increasing cycle numbers. Then after a first intermediate anneal (indicated by a vertical black arrow 1 pointing down), the initial stroke is fully recovered and decreases again until the next intermediate anneal $n=2$. As can be seen in Fig. 10, this in-situ spring actuator rejuvenation treatment can be repeated several times. In Fig. 10, the first four rejuvenation anneals fully re-establish the initial stroke.

For higher numbers $\mathrm{n}$ of anneals, the recovered stroke decreases slightly but its decrease during cycling is less 


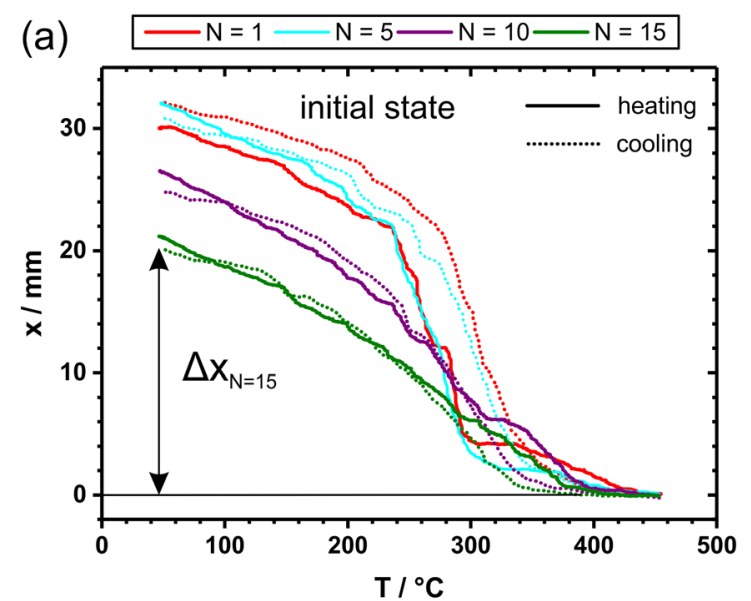

(c) $\square \mathrm{N}=61-\mathrm{N}=65-\mathrm{N}=70-\mathrm{N}=75$

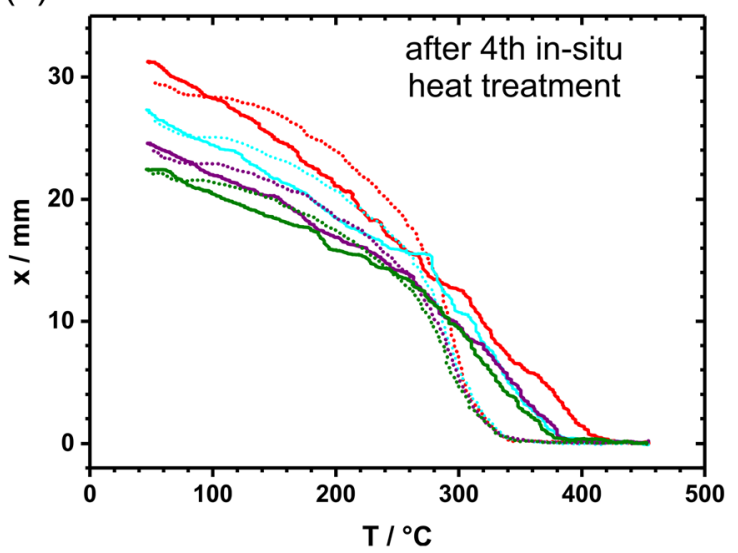

Fig. $9 \mathrm{Ti}_{75} \mathrm{Ta}_{25}$ spring actuator response monitored at heating/cooling rates of $10 \mathrm{~K} / \mathrm{s}$ up to $T_{\max }=450{ }^{\circ} \mathrm{C}$ (same heating/cooling rates as applied in the tests shown in Fig. 8. Intermediate $10 \mathrm{~s}$ in-situ anneals are imposed in 15 cycle intervals. a Evolution of $15 x(T)$ cycles in the initial state. b Cycles 16-30 after a first intermediate

pronounced. This decrease can be quantified by the slope of the dashed black lines compiling stroke data for one condition. These negative slopes in $\mathrm{mm} /$ cycle can be thought of as degradation rates and are plotted in Fig. 11 as a function of the numbers $\mathrm{n}$ of anneals. The results shown in Fig. 11 suggest that there is a beneficial microstructural stabilization effect resulting in lower degradation rates with increasing numbers of $N$ and $n$.

\section{Comparison of $\mathrm{Ti}_{75} \mathrm{Ta}_{25}$ with $\mathrm{Ni}_{50} \mathrm{Ti}_{50}$}

Figure 12 shows a comparison between spring actuators of $\mathrm{Ni}_{50} \mathrm{Ti}_{50}$ and $\mathrm{Ti}_{75} \mathrm{Ta}_{25}$. For this comparison, $\mathrm{Ni}_{50} \mathrm{Ti}_{50}$ spring actuators were manufactured as described previously $[35,36,40]$, such that they have identical geometries as the $\mathrm{Ti}-\mathrm{Ta}$ actuators studied in the present work. They were tested in the same rig as the $\mathrm{Ti}_{75} \mathrm{Ta}_{25}$ springs described above. An effort was made to establish similar types of starting microstructures (fine austenite grains as shown for
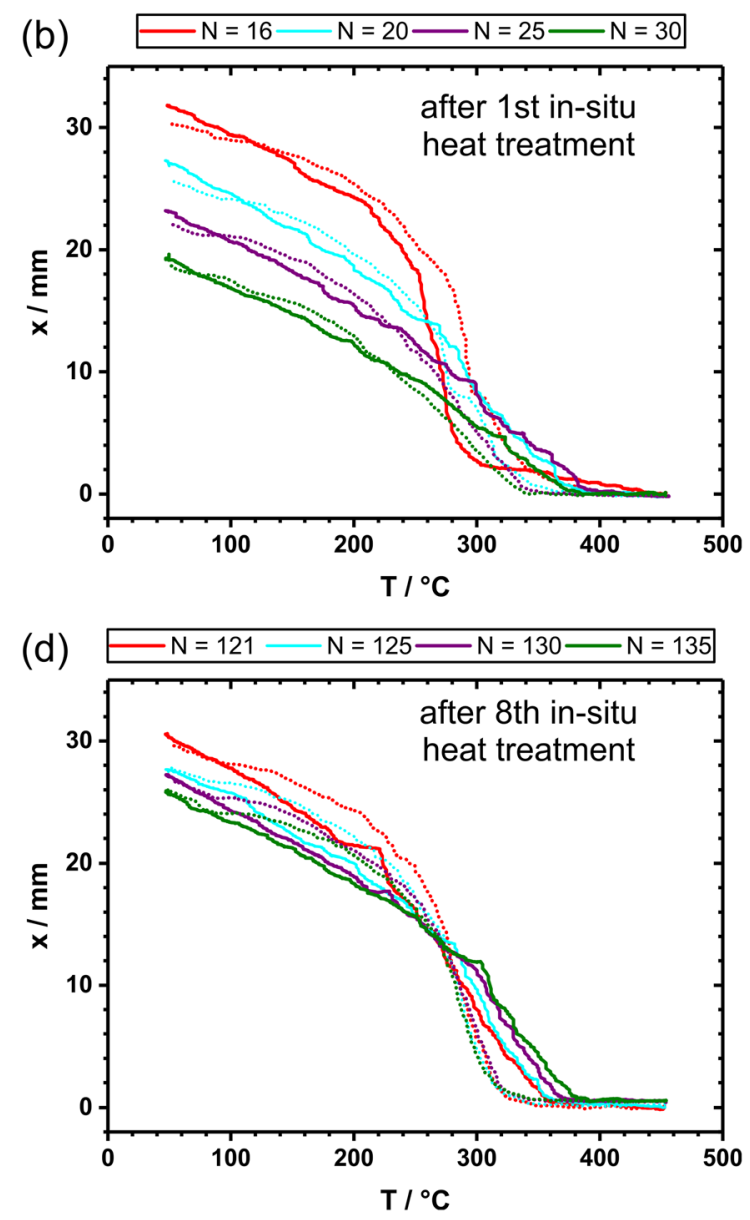

$10 \mathrm{~s}$ in-situ anneal at $550{ }^{\circ} \mathrm{C}$-the actuator performance is fully reestablished. c Cycles $61-75$ after four 15 cycle interval intermediate anneals. d Cycles 121-135 after eight 15 cycle interval intermediate anneals. For details see text

$\mathrm{Ti}_{75} \mathrm{Ta}_{25}$ in Fig. 3b). Ni-Ti springs were tested under the same end load and cycled between 25 and $120{ }^{\circ} \mathrm{C}$. Figure 12 shows $x(T)$-curves which were recorded in experiments taken through to 121 cycles. The actuator response to thermo mechanical cycling is presented for cycles 1,16 and 121. $\mathrm{Ti}_{75} \mathrm{Ta}_{25}$ actuator spring testing was performed applying intermediate rejuvenation heat treatments in 15 cycles intervals. Figure 12 shows that the Ni-Ti actuator operates at lower temperatures (switching temperature: close to $70{ }^{\circ} \mathrm{C}$ ) within narrower temperature windows and features higher strokes $(\Delta x>60 \mathrm{~mm})$ which do not significantly evolve with increasing numbers of thermo mechanical cycles. It shows the expected behavior in the sense that on cooling, the temperature $\mathrm{M}_{\mathrm{S}}$, where austenite re-transforms to martensite, is lower than the temperature $\mathrm{A}_{\mathrm{S}}$ which is observed on heating. However, one can see that there is an irreversible elongation associated with actuation. The $\mathrm{Ti}_{75} \mathrm{Ta}_{25}$ actuator does not suffer from a strong accumulation of irreversible plastic strain. It 


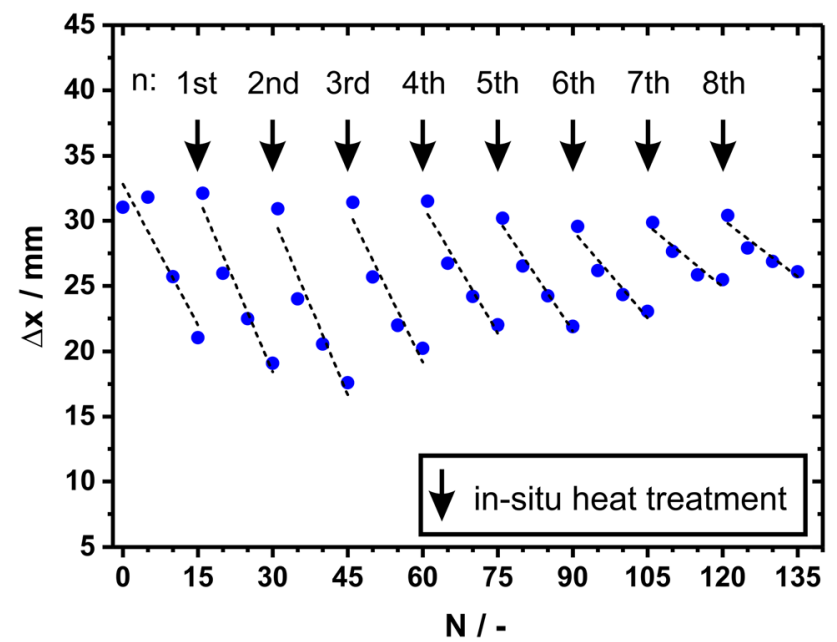

Fig. 10 Actuator stroke rejuvenation during $50-450{ }^{\circ} \mathrm{C}$ cycling (data retrieved from experiments shown in Fig. 9). The stroke $\Delta x$ plotted as a function of cycle number $N$. As indicated, 8 intermediate anneals $\left(550{ }^{\circ} \mathrm{C}, 10 \mathrm{~s}\right)$ allow to counteract functional fatigue

combines higher switching temperatures (above $250{ }^{\circ} \mathrm{C}$ range) with lower strokes (of the order of $30 \mathrm{~mm}$ ) which hardly change with increasing cycle numbers.

\section{Discussion}

\section{Spring Processing and Testing}

When exploring the potential of SMAs for actuator applications, one needs to be able to manufacture and test spring actuators [46]. In the present work we have described a procedure which allows to manufacture spring actuators from small, chemically and microstructurally homogeneous ingots. This method is documented in Figs. 1, 2, 3, 4, 5 and 6 and builds on previous experience on spring actuator manufacturing and testing $[35,36,40]$. The difficulty in working with the Ti-Ta system is the high melting point of Ta (close to $3000{ }^{\circ} \mathrm{C}$ ), which is close to the boiling point of $\mathrm{Ti}$. As a consequence, one has to pay attention to $\mathrm{Ti}$ losses due to evaporation. After mixing of $\mathrm{Ti}$ and $\mathrm{Ta}$, the $\mathrm{Ti}_{75} \mathrm{Ta}_{25}$ alloy considered in the present work has a liquidus temperature close to $2200{ }^{\circ} \mathrm{C}$ [38]. It is difficult to reach such temperatures by vacuum induction melting (VIM), which allows to make large ingots. In the present work we show how a small arc melter can be used for melting (to produce the alloy) and welding (to reach a critical volume required for spring processing). We also show how the functional fatigue test apparatus developed previously $[35,36,40]$ was modified to allow for higher test temperatures. Two further aspects make it more difficult to work with a Ti-Ta alloy than with the industry standard Ni-Ti. First, one has to take care of the $\alpha$-case

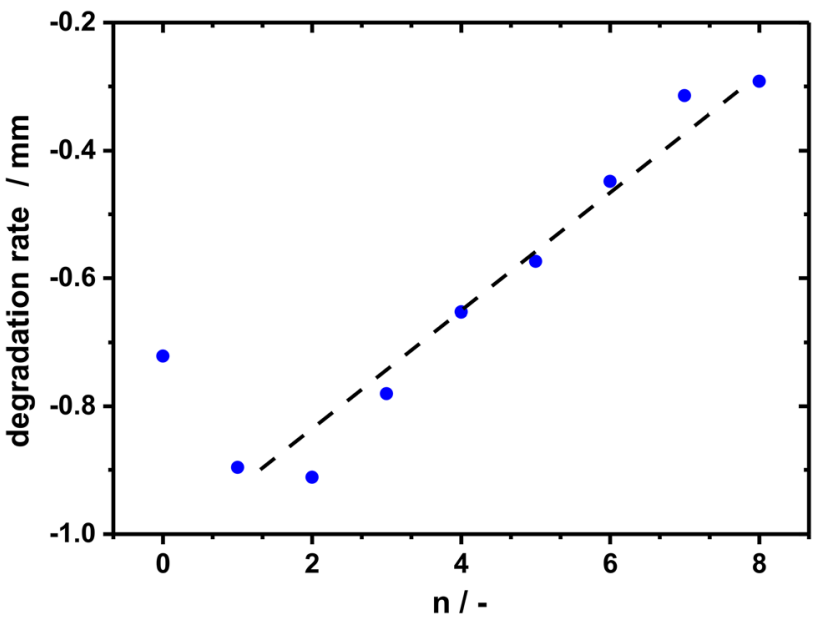

Fig. 11 Evolution of the degradation rate (slopes in Fig. 10) presented as a coupled effect of cycle numbers $N$ and numbers $n$ of intermediate anneals

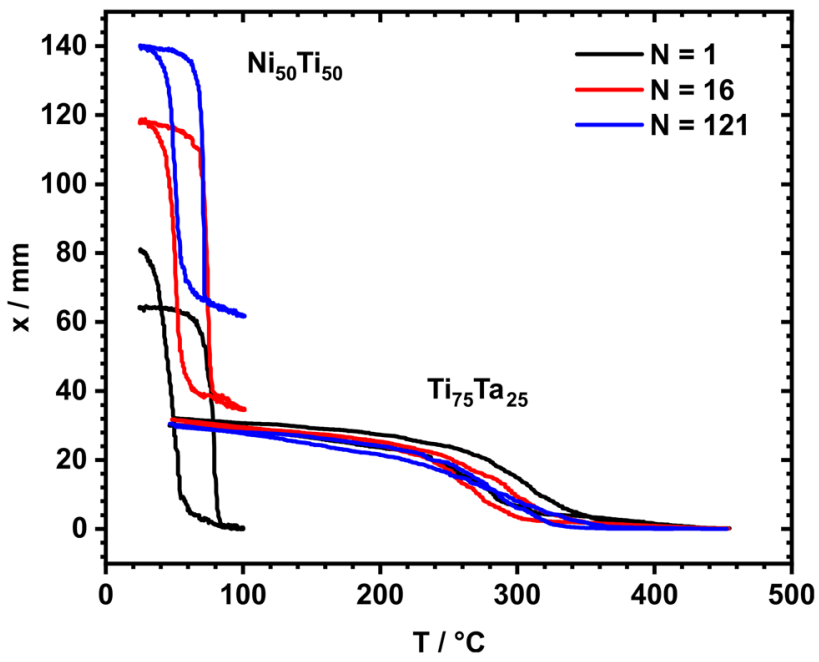

Fig. 12 Comparison spring actuator performance. $\mathrm{Ni}_{50} \mathrm{Ti}_{50}$ and $\mathrm{Ti}_{75} \mathrm{Ta}_{25}$ actuator springs with similar fine austenite grain sizes were tested in the rig shown in Fig. 3. $\mathrm{Ni}_{50} \mathrm{Ti}_{50}$ was cycled between 25 and $120{ }^{\circ} \mathrm{C}$. $\mathrm{Ti}_{75} \mathrm{Ta}_{25}$ was cycled between 25 and $450{ }^{\circ} \mathrm{C}$ (with intermediate rejuvenation annealing steps applied in 15 cycle intervals). For details see text

formation [23], which has a detrimental effect on the surface integrity, Fig. 4. Second, one must perform the intermediate heat treatments and the shape setting treatments at higher temperatures to avoid the formation of detrimental phases ( $\alpha$ and $\omega$ ) [34].

\section{$\omega$-Phase Formation}

Materials research on the Ti-Ta system has shown that the formation of $\omega$-phase represents the main cause for functional degradation as it impedes the formation of martensite, e.g. $[11,21,30,32]$. The $\omega$-phase quickly forms at 
temperatures which are passed through during thermal activation and therefore cannot be avoided. It has been documented in literature that the $\omega$-phase forms from $\beta$-Ti by a collapse of [111 $]_{\beta}$ planes [47]. As the kinetics of this process are very fast $[34,47]$, the exposure times to critical temperature ranges, i.e. to slightly elevated temperatures where the HTSMA is in its austenitic state, need to be kept at a minimum. The DSC curves in Fig. 7 suggest that temperatures between 300 and $480{ }^{\circ} \mathrm{C}$ are critical as $\omega$ phase forms in $\mathrm{Ti}_{75} \mathrm{Ta}_{25}$ within this range. To use $\mathrm{Ti}-\mathrm{Ta}$ alloys as spring actuators one has to apply the intermediate rejuvenation anneal, which was first proposed by Niendorf et al. [42] for linear actuators and for an alloy of type $\mathrm{Ti}_{70} \mathrm{Ta}_{30}$. In the present work we investigated $\mathrm{Ti}_{75} \mathrm{Ta}_{25}$ with a significantly higher $\mathrm{M}_{\mathrm{S}}$ temperature and we perform the rejuvenation heat treatments during spring actuation, as documented in Figs. 9, 10 and 11. Integrating these rejuvenation steps in between short actuation sequences allows to keep the detrimental effect of the $\omega$-phase in $\mathrm{Ti}_{75} \mathrm{Ta}_{25}$ actuators at a minimum. The alternative is, to heat the actuator in each cycle to temperatures which are high enough for $\omega$-phase dissolution, Fig. $8 \mathrm{~b}$. This has the drawback, however, that creep deformation results in irreversible plastic deformation and thus in a significant change of spring actuator geometry [32]. One may have the concern that an intermediate rejuvenation anneal can promote surface oxidation and thus affect structural fatigue. However, this seems to be unlikely as no significant growth of oxide layers is expected for the imposed heat treatment conditions $\left(550{ }^{\circ} \mathrm{C}, 10 \mathrm{~s}\right)$ for Ti-Ta SMAs [27]. Figures 9 and 10 show one striking phenomenon: Applying several rejuvenation anneals provides a stabilization effect. With increasing number of thermo-mechanical cycles/rejuvenation anneals, the functional degradation per cycle decreases. This type of behavior is known for other SMAs such as $\mathrm{Ni}-\mathrm{Ti}$, where functional fatigue is governed by the formation of dislocations which can stabilize martensite $[37,46]$. However, the origin for this behavior in Ti-Ta HTSMAs, where degradation relies on $\omega$-phase formation, is not clear at present. Further work is required to study this effect and to analyze whether it can be exploited to improve functional stability, e.g. by applying a training treatment.

\section{Unusual Cooling Behavior}

The fact that on cooling from the austenite regime one finds that $M_{S}$ is higher than the $A_{F}$ observed during heating is unusual. It is not observed in the case linear Ti-Ta actuators [32]. This suggests that the effect is related to the spring geometry and the associated stress state. Further work is required to clarify this point.

\section{Summary and Conclusions}

The present work demonstrates how $\mathrm{Ti}_{75} \mathrm{Ta}_{25}$ high-temperature shape memory spring actuators can be processed and assessed on the lab scale. From the results obtained in the present work the following conclusions can be drawn: One can successfully develop an experimental procedure which allows to produce $\mathrm{Ti}_{75} \mathrm{Ta}_{25}$ spring actuators on the lab scale. It is shown how one can combine small scale arc melting with arc welding to obtain sufficiently large material volumes. Thermo mechanical treatments, swaging, wire drawing and actuator spring manufacturing are then documented. It is then shown how spring actuators can be tested in a dedicated test rig, which allows to determine actuation temperatures and the evolution of spring geometry and actuator strokes with cycle numbers. The functional characteristic of $\mathrm{Ti}_{75} \mathrm{Ta}_{25}$ actuators is strongly affected by the precipitation of the $\omega$-phase in the temperature range between 300 and $480{ }^{\circ} \mathrm{C}$, above the temperature $\mathrm{A}_{\mathrm{S}}$, where martensite transforms to austenite. The precipitation of $\omega$-phase, which cannot be avoided during heating, suppresses the martensitic transformation. A clever temperature management during actuation is required to keep the detrimental effect of the $\omega$-phase at a minimum. This includes fast heating and cooling periods to minimize the time available for precipitation, re-dissolving the $\omega$ phase by applying high enough maximum temperatures and by introducing intermediate rejuvenation anneals. The present study has demonstrated, that $\mathrm{Ti}_{75} \mathrm{Ta}_{25}$ can be used to manufacture high-temperature shape memory actuators. Their performance can be improved when intermediate rejuvenation anneals are applied, which remove $\omega$-phase precipitates. In direct comparison to NiTi spring actuators, one finds that under optimized operation conditions (high enough $\left.T_{\max }\right) \mathrm{Ti}_{75} \mathrm{Ta}_{25}$ allows smaller stroke actuation at significantly higher temperatures. However, applying intermediate rejuvenation anneals allows to outperform binary Ni-Ti SMAs in terms of functional fatigue.

Acknowledgements The authors acknowledged funding by the German Research Association (DFG) through the Research Group FOR 1766 on High Temperature Shape Memory Alloys co-ordinated by Prof. H.J. Maier from the University of Hannover. We acknowledge the fruitful collaboration with all FOR 1766 PIs and researchers over the years.

Open Access This article is licensed under a Creative Commons Attribution 4.0 International License, which permits use, sharing, adaptation, distribution and reproduction in any medium or format, as long as you give appropriate credit to the original author(s) and the source, provide a link to the Creative Commons licence, and indicate if changes were made. The images or other third party material in this article are included in the article's Creative Commons licence, unless indicated otherwise in a credit line to the material. If material is not included in the article's Creative Commons licence and your intended use is not permitted by statutory regulation or exceeds the permitted 
use, you will need to obtain permission directly from the copyright holder. To view a copy of this licence, visit http://creativecommons. org/licenses/by/4.0/.

Funding Open Access funding enabled and organized by Projekt DEAL.

\section{References}

1. Otsuka K, Wayman CM (eds) (1998) Shape memory materials. Cambridge University Press, Cambridge

2. Van Humbeeck J (1999) Non-medical applications of shape memory alloys. Mater Sci Eng A273-A275:134-148

3. Duerig T, Pelton A, Stöckel D (1999) An overview of Nitinol medical applications. Mater Sci Eng A273-A275:149-160

4. Van Humbeeck J (2001) Shape memory alloys: a material and a technology. Adv Eng Mater 3:837-850

5. Otsuka K, Ren X (2005) Physical metallurgy of Ti-Ni based shape memory alloys. Prog Mater Sci 59:511-678

6. Frenzel J, Zhang Z, Neuking K, Eggeler G (2004) High quality vacuum induction melting of small quantities of NiTi shape memory alloys in graphite crucibles. J Alloys Compd 385:214-223

7. Loebel R, Thienhaus S, Savan A, Ludwig A (2008) Combinatorial fabrication and high-throughput characterization of a $\mathrm{Ti}-$ $\mathrm{Ni}-\mathrm{Cu}$ shape memory thin film composition spread. Mater Sci Eng A 481:151-155

8. Elahinia MH, Hashemi M, Tabesh M, Bhaduri SB (2012) Manufacturing and processing of NiTi implants: a review. Prog Mater Sci 57:911-946

9. Elahinia M, Moghaddam NS, Adani MT, Amerinatanzi A, Bimber BA, Hamilton RF (2016) Fabrication of NiTi through additive manufacturing: a review. Prog Mater Sci 83:630-663

10. Van Humbeeck J (2018) Additive manufacturing of shape memory alloys. Shape Mem Superelasticity 4:309-312

11. Kim HY, Miyazaki S (2018) Ni-free Ti-based shape memory alloys. Butterworth-Heinemann/Elsevier, Amsterdam

12. Firstov GS, Kosorukova TA, Koval YN, Odnosum VV (2015) High entropy shape memory alloys. Mater Today 2:499-503

13. Firstov GS, Kosorukova TA, Koval YN, Verhovlyuk PA (2015) Directions for high-temperatrure shape memory alloys' improvement: straight way to high entropy materials? Shape Mem Superelasticity 1:400-407

14. Hinte C, Barienti K, Steinbrucker J, Hartmann JM, Gerstein G, Herbst S, Piorunek D, Frenzel J, Fantin A, Maier HJ (2020) The effect of increasing chemical complexity on the mechanical and functional behavior of NiTi-related shape memory alloys. Shape Mem Superelasticity 6:181-190

15. Piorunek D, Frenzel J, Jöns N, Somsen C, Eggeler G (2020) Chemical complexity, microstructure and martensitic transformation in high entropy shape memory alloys. Intermetallics 122:106792

16. Firstov GS, Van Humbeeck J, Koval Y (2004) High-temperature shape memory alloys—-some recent developments. Mater Sci Eng A 378:2-10

17. Firstov GS, Van Humbeeck J, Koval YN (2006) High temperature shape memory alloys and prospects. J Intell Mater Syst Struct 17:1041-1047

18. Ma J, Karaman I, Noebe RD (2010) High temperature shape memory alloys. Int Mater Rev 55:257-315

19. Motemani Y, Buenconsejo PJS, Ludwig A (2015) Recent developments in high-temperature shape memory thin films. Shape Mem Superelasticity 1:450-459
20. Miyazaki S, Kim HY, Buenconsejo PJS (2009) Development of high temperature TiTa shape memory alloys. In: Sittner P, Paidar V, Heller L, Seiner H (eds) Proceedings of ESOMAT 2009—8th European Symposium on Martensitic transformations. Article number: 01003

21. Buenconsejo PJS, Kim HY, Hosoda H, Miyazaki S (2009) Shape memory behavior of Ti-Ta and its potential as a high-temperature shape memory alloy. Acta Mater 57:1068-1077

22. Buenconsejo PJS, Kim HY, Miyazaki S (2011) Novel betaTiTaAl alloys with excellent cold workability and a stable hightemperature shape memory effect. Scr Mater 64:1114-1117

23. Lütjering G, Williams JC (2007) Titanium. Springer, Heidelberg

24. Zhang J, Rynko R, Frenzel J, Somsen C, Eggeler G (2014) Ingot metallurgy and microstructural characterization of Ti-Ta alloys. Int J Mater Res 105:156-167

25. DFG research group High Temperature Shape Memory Alloys (FOR 1766, co-ordinated by H.J. Maier, 2012-2018)

26. Rynko R, Marquardt A, Paulsen A, Frenzel J, Somsen C, Eggeler G (2015) Microstructural evolution in a Ti-Ta high-temperature shape memory alloy during creep. Int J Mater Res 106:331-341

27. Langenkämper D, Paulsen A, Somsen C, Frenzel J, Eggeler G (2019) On the oxidation behavior and its influence on the martensitic transformation of Ti-Ta high temperature shape memory alloys. Shape Mem Superelasticity 5:63-72

28. Ferrari A, Paulsen A, Frenzel J, Rogal J, Eggeler G, Drautz R (2018) Unusual composition dependence of transformation temperatures in Ti-Ta-X shape memory alloys. Phys Rev Mater 2:073609

29. Ferrari A, Kadletz PM, Chakraborty T, Liao KY, Langenkämper D, Motemani Y, Paulsen A, Lysogorskiy Y, Frenzel J, Rogal J, Ludwig A, Somsen C, Drautz R, Schmahl WW (2019) Reconciling experimental and theoretical data in the structural analysis of Ti-Ta shape-memory alloys. Shape Mem Superelasticity $5: 6-15$

30. Ferrari A, Paulsen A, Langenkämper D, Piorunek D, Somsen C, Frenzel J, Rogal J, Eggeler G, Drautz R (2019) Discovery of omega-free high-temperature Ti-Ta-X shape memory alloys from first principles calculations. Phys Rev Mater 3:103605

31. Niendorf T, Krooß P, Batyrsina E, Paulsen A, Motemani Y, Ludwig A, Buenconsejo P, Frenzel J, Eggeler G, Maier HJ (2015) Functional and structural fatigue of titanium tantalum high temperature shape memory alloys. Mater Sci Eng A 620:359-366

32. Maier HJ, Karsten E, Paulsen A, Langenkämper D, Decker P, Frenzel J, Somsen C, Ludwig A, Eggeler G, Niendorf T (2017) Microstructural evolution and functional fatigue of a Ti-25Ta high-temperature shape memory alloy. J Mater Res 32:4287-4295

33. Krooss P, Lauhoff C, Langenkämper D, Paulsen A, Reul A, Degener S, Aminforough B, Frenzel J, Somsen C, Schmahl WW, Eggeler G, Maier HJ, Niendorf T (2019) Impact of heatingcooling rates on the functional properties of Ti-20Ta-5Al high temperature shape memory alloys. Shape Mem Superelasticity 5:95-105

34. Paulsen A, Frenzel J, Langenkämper D, Rynko R, Kadletz P, Grossmann L, Schmahl WW, Somsen C, Eggeler G (2019) A kinetic study on the on the evolution of martensitic transformation behavior and microstructures in TiTa high temperature shape memory alloys during aging. Shape Mem Superelasticity 5:16-31

35. Grossmann C, Frenzel J, Sampath V, Depka T, Oppenkowski A, Somsen C, Neuking K, Theisen W, Eggeler G (2008) Processing and property assessment of $\mathrm{NiTi}$ and $\mathrm{NiTiCu}$ shape memory actuator springs. Mat wiss Werkstofftechn 39:499-510

36. Grossmann C, Frenzel J, Sampath V, Depka T, Eggeler G (2009) Elementary transformation and deformation processes and the cyclic stability of $\mathrm{NiTi}$ and $\mathrm{NiTiCu}$ shape memory actuator springs. Metall Mater Trans A 40:2530-2544 
37. Frenzel J, George EP, Dlouhy A, Somsen C, Wagner MFX, Eggeler G (2010) Influence of $\mathrm{Ni}$ on martensitic phase transformations in NiTi shape memory alloys. Acta Mater 58:3444-3458

38. Murray JL (1981) The Ta-Ti (Tantalum-Titanium) system. Bull Alloy Phase Diagr 2:62-66

39. Weck E, Leistner E (1983) Metallographic instructions for color etchants by immersion, Part II: Beraha colour etchants and their different variants. Deutscher Verlag für Schweißtechnik, Düsseldorf

40. Frenzel J, Burow JA, Payton EJ, Rezanka S, Eggeler G (2011) Improvement of NiTi shape memory actuator performance through ultra-fine grained and nanocrystalline microstructures. Adv Eng Mater 13(4):256-268

41. Paulsen A (2019) Herstellung, Eigenschaften und Phasenstabilitäten von Hochtemperaturformgedächtnislegierungen auf Basis von Ti-Ta, Dr.-Ing. Thesis, Ruhr University Bochum

42. Niendorf T, Krooß P, Bartyrsina E, Paulsen A, Frenzel J, Eggeler G, Maier HJ (2014) On the functional degradation of binary titanium tantalum high-temperature shape memory alloys-a new concept for fatigue life extension. Funct Mater Lett 7:1450042
43. Langenkämper D (2019) Mikrostrukturelle Untersuchungen zur Phasenstabilität und zum Oxidationsverhalten im System TiTa, Dr.-Ing. Thesis, Ruhr University Bochum, Bochum

44. Rynko R (2015) Mikrostrukturelle Untersuchungen von thermisch und thermomechanisch induzierten Strukturbildungsprozessen in Ti-Ta HochtemperaturFormgedächtnislegierungen, Dr.-Ing. Thesis, Ruhr University Bochum, Bochum

45. Petrzhik MI, Fedotov SG, Kovneristyi YK, Zhebyneva NF (1992) Effect of thermal cycling on the structure of quenched alloys of the Ti-Ta-Nb system. Metal Sci Heat Treat 34:190-193 (in Russian)

46. Frenzel J (2020) On the importance of structural and functional fatigue in shape memory technology. Shape Mem Superelasticity 6:213-222

47. Sikka SK, Vohra YK, Chidambaram R (1982) Omega-phase in materials. Prog Mater Sci 27:245-310

Publisher's Note Springer Nature remains neutral with regard to jurisdictional claims in published maps and institutional affiliations. 